\title{
Interfacial aging in composite insulators as a result of partial discharge activity
}

DOI:

10.1109/EIC.2017.8004690

\section{Document Version}

Accepted author manuscript

Link to publication record in Manchester Research Explorer

\section{Citation for published version (APA):}

Bastidas, P., \& Rowland, S. (2018). Interfacial aging in composite insulators as a result of partial discharge activity. In Proceedings of the IEEE Electrical Insulation Conference, Baltimore 2017 https://doi.org/10.1109/EIC.2017.8004690

\section{Published in:}

Proceedings of the IEEE Electrical Insulation Conference, Baltimore 2017

\section{Citing this paper}

Please note that where the full-text provided on Manchester Research Explorer is the Author Accepted Manuscript or Proof version this may differ from the final Published version. If citing, it is advised that you check and use the publisher's definitive version.

\section{General rights}

Copyright and moral rights for the publications made accessible in the Research Explorer are retained by the authors and/or other copyright owners and it is a condition of accessing publications that users recognise and abide by the legal requirements associated with these rights.

\section{Takedown policy}

If you believe that this document breaches copyright please refer to the University of Manchester's Takedown Procedures [http://man.ac.uk/04Y6Bo] or contact uml.scholarlycommunications@manchester.ac.uk providing relevant details, so we can investigate your claim.

\section{OPEN ACCESS}




\title{
Interfacial aging in composite insulators as a result of partial discharge activity
}

\author{
Pablo D. Bastidas and Simon M. Rowland \\ School of Electrical and Electronic Engineering \\ The University of Manchester \\ Manchester, United Kingdom \\ s.rowland@manchester.ac.uk
}

\begin{abstract}
High voltage outdoor composite insulators used on transmission lines can be subject to degradation due to electrical discharge activity at the core-sheath interface. A methodology is described to explore the effect of de-bonding or loss of adhesion between the sheath and core in composite insulators. The use of planar geometry materials allows interfacial pressure to be varied and facilitates physical and optical imaging of the tracking as it grows and chemical analysis of the samples after aging. The associated electrode geometry allowed the tracking to develop in a constant field, unaffected by the earth electrode. Low pressure between the materials accelerated the growth the tracks. A correlation between partial discharge magnitude and track development is identified. Electrical tree growth was also observed penetrating the epoxy resin, initiated from the interfacial tracks.
\end{abstract}

Keywords - pressure, interface, epoxy resin, silicone rubber, tracking, composite insulators, treeing, partial discharge, PD

\section{INTRODUCTION}

Composite insulators used in $\mathrm{HV}$ transmission lines provide outstanding mechanical and dielectric properties, and have become commodity products, in competition with ceramic and glass insulators [1]. However, issues concerning interfacial degradation have been reported for as long as this type of insulator has been used [2]. A key area of concern is the interface between the pultruded glass-fibre core and the silicone rubber ( $\mathrm{SiR}$ ) sheath, and this makes the quality assurance of design and production critical.

Composite insulators are exposed to various dynamic mechanical loads that involve compression, tension and torsion from installation, maintenance, aeolian vibration, sub-span oscillations and conductor galloping. Unless insulators are appropriately designed, manufactured and installed, the result may be material fatigue, delamination and cracking. In particular the adhesive bond between the core and sheath may be compromised [3],[4],[5]. Such physical aging events can result in regions of low density or even elongated voids. If such low density regions are in areas of high electric fields, enhanced electron mobility will result in high energy electrons and internal discharge activity. This in turn will cause permanent damage at the interface [4]. Deposits of conductive carbon may also result, leading ultimately to interfacial breakdown [6],[7],[8].

\section{PREVIOUS TEST REGIMES}

Models for interfacial aging remain poorly defined. Several studies have investigated the effect of surface roughness and contact pressure using compression forces to remove air bubbles at interfaces and to investigate the role of adhesives or grease in cable joints [9],[10],[11]. Hasheminezhad and Ildstad [12] proposed a model based on mechanical pressure, surface roughness and the resulting dimensions of interfacial voids. Gu and He [13] investigated interfacial breakdown at XLPE/SiR interfaces. Two electrodes with radii of $2.5 \mathrm{~mm}$ were sandwiched between the dielectrics and compressed at $20 \mathrm{kPa}$. It was observed that a large micro-cavity readily initiated electrical discharges, with associated interfacial tracking and subsequent breakdown.

Anderson et al [14] studied the strength of primer bonding between SiR and epoxy slabs. A wire of $75 \mu \mathrm{m}$ radius provided field enhancement and samples were aged for 330 hours at $10 \mathrm{kV} \mathrm{AC}$. White powder resulted on the silicone rubber surface, whereas discharge activity caused cracks on the epoxy surface. Kobayashi et al [15] investigated the effects of permittivity and interfacial pressure at epoxy/ethylene propylene rubber and ethylene propylene rubber/LDPE interfaces. Testing used two aluminum foil electrodes, separated by $5 \mathrm{~mm}$ in the interface. Electrical tree characteristics varied with the mechanical pressure applied to the samples. At $3 \mathrm{kgf} / \mathrm{cm}^{2}$, treeing occurred along the interface, whereas at $15 \mathrm{kgf} / \mathrm{cm}^{2}$ electrical trees grew into the bulk of the EP slab.

A cylindrical configuration (long-rod) was presented by the authors previously [16]. This report presents an experimental system, using planar insulating materials. A key feature of the design used is that only one electrode is embedded in the interface, so that the field in which the track develops is not principally determined by the trackearth distance. This requires high voltage testing but more closely matches the aging found in composite insulators. $\mathrm{SiR}$ and epoxy resin slabs have been subjected to various interfacial pressures, whilst electrically stressed with AC voltages for 96 hours.

\section{EXPERIMENTAL}

Samples were prepared from $50 \times 150 \mathrm{~mm}$ plaques of 5 $\mathrm{mm}$ thick unfilled epoxy and $3 \mathrm{~mm}$ thick unfilled high 
temperature vulcanized SiR. A $45 \mu \mathrm{m}$ diameter stainless steel wire was placed between the dielectrics, which were then pressed together with a force of up to $60 \mathrm{kPa}$. The wire formed an electrode which enhanced the local electrical field and was found to reproducibly initiate partial discharge activity. The EP was fabricated using Araldite-LY5052 resin and Aradur-HY5052 hardener mixed in the ratio of 100:38 by weight. The mixture was then degassed in a vacuum chamber before being dispensed into a frame over a $1 \mathrm{~mm}$ thick polycarbonate sheet. The resulting plaque had a smooth surface finish, with a surface roughness of $\sim 0.3 \mu \mathrm{m}$, whilst the SiR plaques had a surface roughness of $\sim 0.7 \mu \mathrm{m}$. The samples were assembled as follows: the wire and the $\mathrm{SiR}$ plaque were cleaned with propanol, whilst the epoxy was rinsed with deionised water. Both plaques were immediately blown dry with warm air to avoid leaving surface stains. The tip of the wire was formed into a circular shape (a crook) of $\sim 1.2 \mathrm{~mm}$ diameter which was then placed between the dielectrics, forming a controlled field enhancement $40 \mathrm{~mm}$ from the sample's short edge. This is illustrated in Figure 1. The assembly was orientated with the large planes horizontal. It was supported on a glass plate, with the transparent epoxy resin adjacent to the glass so that images of degradation and light emission could be obtained from the underside, whilst a dead weight could be used to impose controlled pressure from the top.

A photograph of the experimental system and a schematic of the electrode configuration is presented in Figures 1 and 2. The distance between the tip of the wire hook and the ground plate was fixed at $90 \mathrm{~mm}$ for all the tests presented here. The gap distances and geometries of external electrodes were designed using FEA to prevent surface discharges. A feature

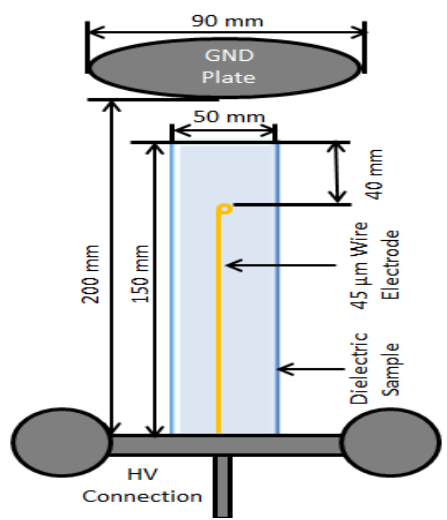

Figure 1. Schematic of the experimental set-up (top view). Not to Scale.

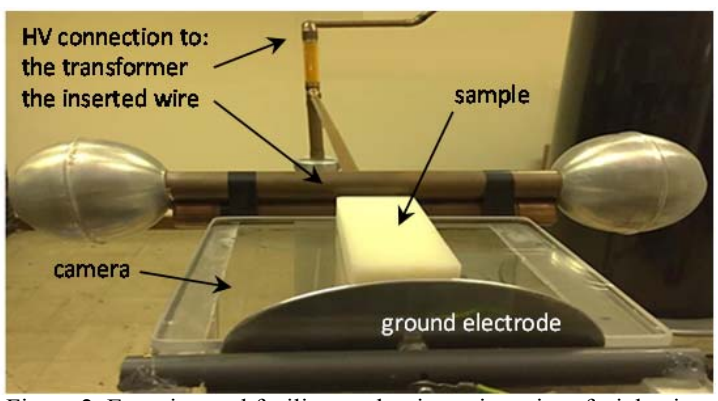

Figure 2. Experimental facility used to investigate interfacial aging in planar insulating samples

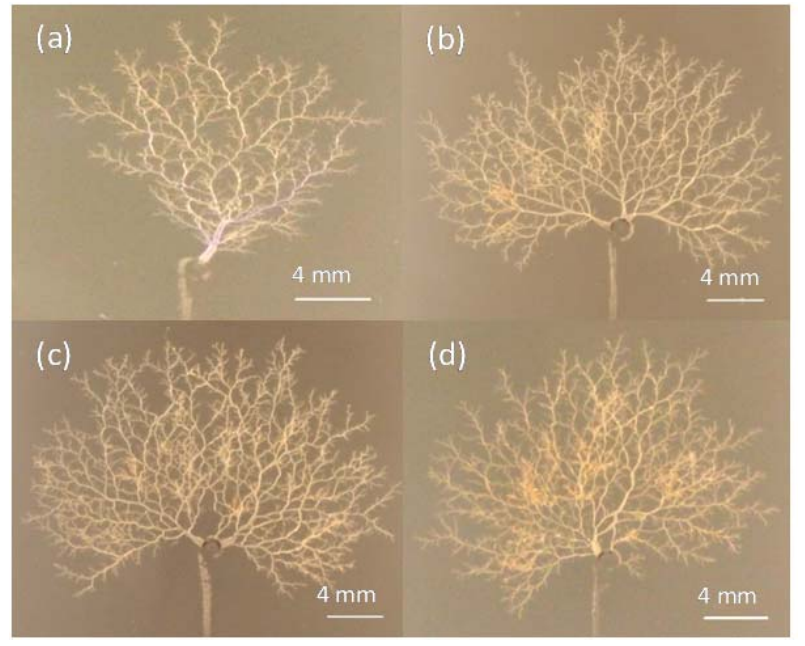

Figure 3. Development of interfacial channels at (a) $0 \mathrm{kPa}$, (b) $20 \mathrm{kPa}$, (c) $40 \mathrm{kPa}$ and (d) $60 \mathrm{kPa}$

TABLE I. PD INCEPTION MAGNITUDES AND VOLTAGES

\begin{tabular}{ccc}
\hline $\begin{array}{c}\text { Pressure } \\
(\mathbf{k P a})\end{array}$ & $\begin{array}{c}\text { Inception magnitude } \\
(\mathbf{p C})\end{array}$ & $\begin{array}{c}\text { Inception voltage } \\
(\mathbf{k V})\end{array}$ \\
\hline 0 & 19.61 & 4.4 \\
20 & 17.02 & 4.3 \\
40 & 13.10 & 4.8 \\
60 & 10.84 & 4.4
\end{tabular}

of the test geometry is that the earth electrode is planar and always distant from the tracking. As a result damage was not accelerated by field enhancement as the track approached a ground electrode, as is often the case in laboratory tests.

Bricks $\left(\varepsilon_{\mathrm{r}}=6\right.$ to 8$)$ were used as weights to vary the mechanical pressure on the samples. This ranged from 0 to $60 \mathrm{kPa}$. To monitor the interfacial activity, partial discharge (PD) magnitudes and the partial discharge inception voltage (PDIV) were recorded using an Omicron MPD600 measurement system. A camera (Canon EOS-1100D) was used to monitor the progression of visible aspects of degradation. AC voltages up to $32 \mathrm{kV}$ were applied to the HV connection (RMS voltage values are exclusively used in this paper).

\section{RESULTS AND DISCUSSION}

Figure 3 gives examples of the visible interfacial channels grown at various mechanical pressures. As can be seen, the structure, color and width and length of the tracking pattern are similar for each sample. Table I shows the measured partial discharge inception voltage. The inception voltages are consistent around $4.5 \mathrm{kV}$, but the $\mathrm{PD}$ inception magnitudes decrease when the mechanical pressure is increased (the PD magnitude is halved by increasing the pressure from 0 to $60 \mathrm{kPa}$ ). This is thought to be due to voids around the wire being closed up at higher pressures. However, it was observed that when the voltage was increased to $30 \mathrm{kV}$, PD magnitudes were measured of $65 \mathrm{pC}$ at $0 \mathrm{kPa}$, and $103 \mathrm{pC}$ at $60 \mathrm{kPa}$, yet at pressures of 20 and 40 $\mathrm{kPa}$, PD magnitudes were recorded above $450 \mathrm{pC}$ : an observation not yet explained.

Figure 4 shows recorded PD activity with the growth in width and length of the interfacial channel pattern. The 
maximum magnitudes were selected and are reported for each second of each test. Correlating visual observations of growth with PD suggests that the maximum PD values in a time period are related to growth in length of the channels, whilst periods of high fluctuations in PD values are related to branching and filling of the area between the main branches.

In Figure 4, the development of PD magnitudes has been categorized into three growth phases, and Table II summarizes the characteristics of each phase, for each sample. These phases are described as follows:

Phase 1: Early growth, characterized by a rapid increase of PD magnitude. Rapid growth in length and width of the fine white observable pattern is seen.

Phase 2: A slower growth in length and width of the tree structure is seen. PDs show a significant fluctuation of maximum magnitudes in each minute. Development of branching is seen between the main channels and an increment in the density of channels is evident.

Phase 3: PDs are no longer growing in magnitude, but show a marked fluctuation in time. Within the damaged region, darkened regions, probably carbon deposits, form in the vicinity $(\sim 190 \mu \mathrm{m})$ of the electrode. The outline of the pattern continues to grow, at a slow constant rate, dependent upon the applied pressure.
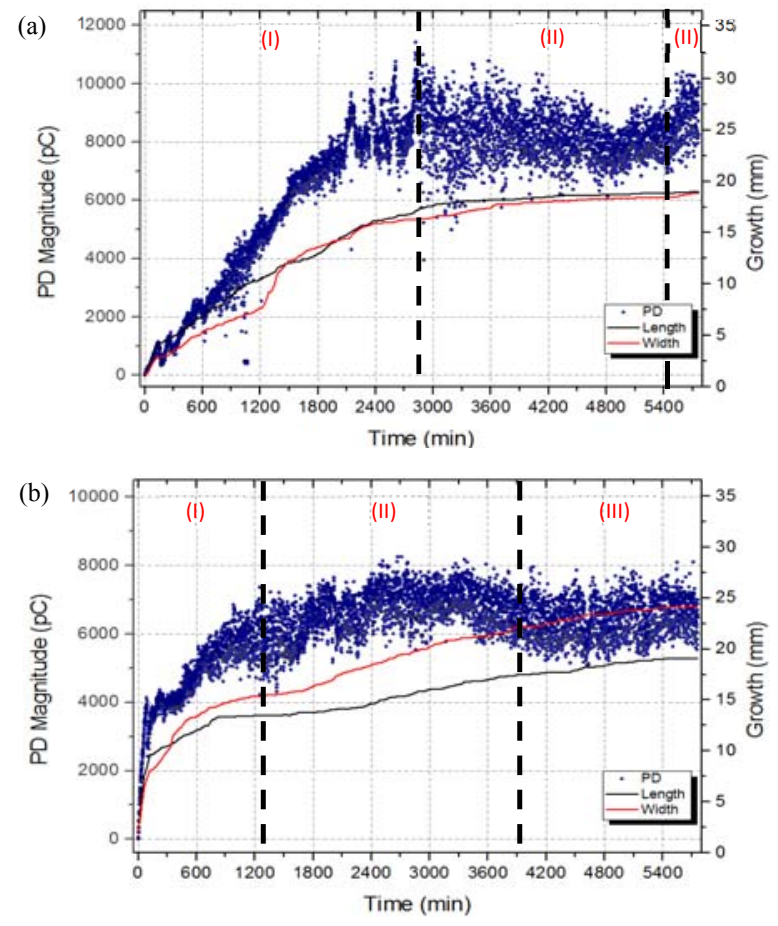

Figure 4. PD magnitudes and interfacial channel growth against time, at (a) $0 \mathrm{kPa}$ and (b) $60 \mathrm{kPa}$

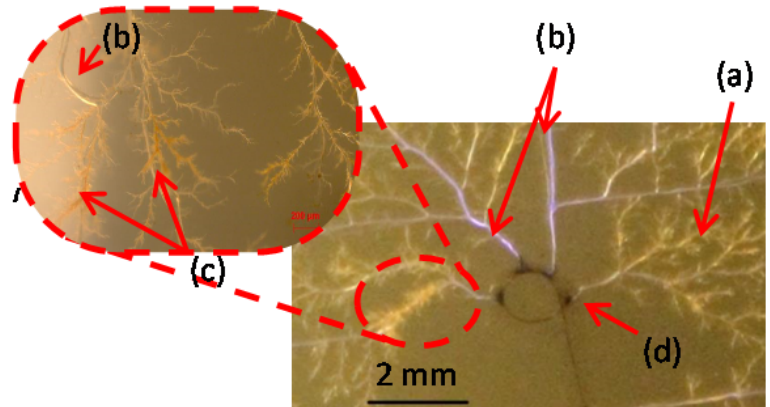

Figure 5. Microscopy of the cross-section from the test at $40 \mathrm{kPa}$. (a) interfacial channels, (b) main branches, (c) electrical trees and (d) carbon conductive deposits. Active discharges in (b) color the branches purple.

In the final phase, the track grew $\sim 70 \mu \mathrm{m}$ in length. This took: 2 hours at $0 \mathrm{kPa} ; 5$ hours at $20 \mathrm{kPa} ; 7$ hours at $40 \mathrm{kPa}$; and 6 hours at $60 \mathrm{kPa}$. This illustrates that a reduction in pressure accelerates the tracking progress.

A key feature of the tracks is whether they are growing in the interface, or in either of the bulk materials. The distinctive interfacial branches are shown in Figure 5. In the geometry tested, tracks developed as trees into the epoxy resin, although this was not seen in the silicone rubber. This is consistent with reports reviewed previously [14],[15]. Figure 6 shows polished cross-sections of the epoxy resin plaques that were observed under an optical microscope. Each sample shows the characteristics and dimensions of the trees which propagated into the bulk of the epoxy. Higher pressures appear to encourage growth of electrical trees into the epoxy resin as reported by Kobayashi et al [15]. This is likely to be due to a reduced tendency to grow within a pressurized interface. At $0 \mathrm{kPa}$ the main channels at the

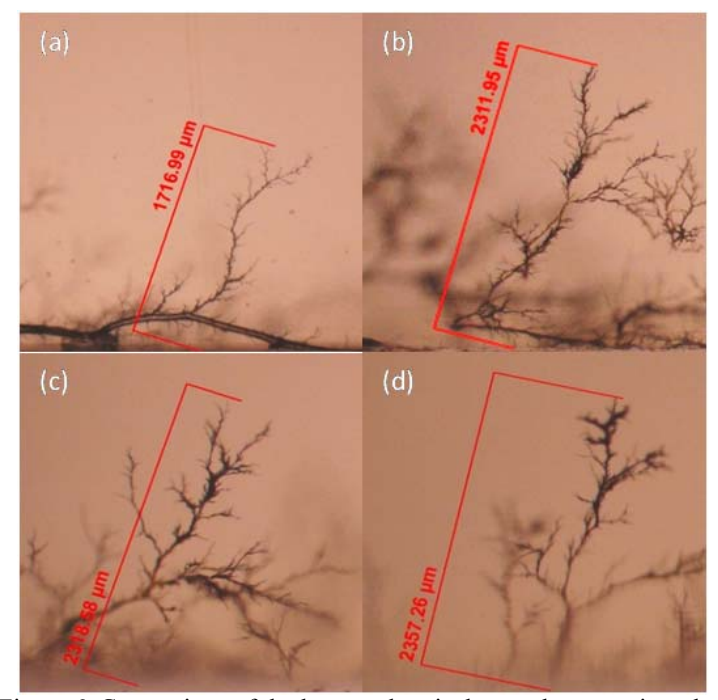

Figure 6. Comparison of the largest electrical trees that grew into the EP plaques (a) $0 \mathrm{kPa}$, (b) $20 \mathrm{kPa}$, (c) $40 \mathrm{kPa}$ and (d) $60 \mathrm{kPa}$.

TABLE II. DEVELOPMENT OF INTERFACIAL CHANNELS ACCORDING TO PD PATTERNS

\begin{tabular}{|c|c|c|c|c|c|c|c|c|c|c|c|c|}
\hline \multirow[b]{2}{*}{ Pressure (kPa) } & \multicolumn{4}{|c|}{ Phase 1} & \multicolumn{4}{|c|}{ Phase 2} & \multicolumn{4}{|c|}{ Phase 3} \\
\hline & 0 & 20 & 40 & 60 & 0 & 20 & 40 & 60 & 0 & 20 & 40 & 60 \\
\hline Length (mm) & 17.5 & 15.1 & 14.4 & 13.4 & 18.8 & 17.6 & 18.5 & 17.4 & 18.9 & 18.6 & 19.5 & 19 \\
\hline $\operatorname{Max} P D(n C)$ & 11.8 & 8 & 9.5 & 7.4 & 11.4 & 8.9 & 12.3 & 9.3 & 11.5 & 9.7 & 11.8 & 8.4 \\
\hline Duration (mins) & 2980 & 1335 & 650 & 1248 & 2594 & 2777 & 2981 & 2699 & 186 & 1648 & 2129 & 1813 \\
\hline
\end{tabular}


interface are wider and in the epoxy small amounts of carbon deposits can be seen at the walls of the hollow channels and also at the tips of the branches. The carbon deposits are more prevalent on the samples at higher applied pressures, and generally, channels become darker and more branched over time. Figure 7(a) shows channel characteristics for the samples at $60 \mathrm{kPa}$, where the channels appear black. Figure 7(b) shows that the tip of the electrical trees consist of carbon deposits. Unlike on the epoxy plaques studied, growth of channels on or in the SiR slab was barely discerned.

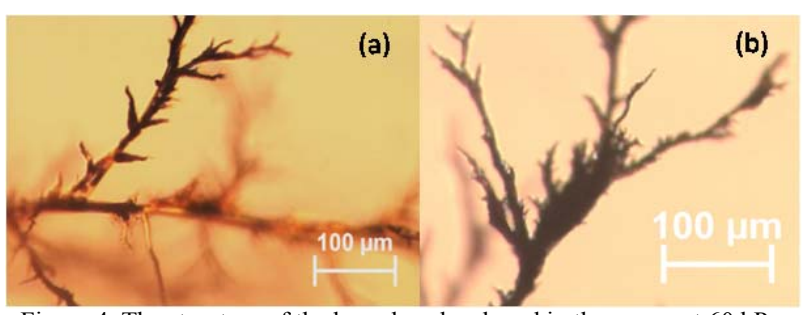

Figure 4. The structure of the branches developed in the epoxy at $60 \mathrm{kPa}$.

(a) the carbon deposits on the walls of the channels,

(b) the tips of the branches

\section{CONCLUSION}

The planar geometry of the materials and transparent nature of epoxy resin has allowed direct observation of interfacial damage as it progressed between the epoxy and silicone rubber. The test geometry allowed the track to grow into a field unaffected by the earth electrode, as it does in a real composite insulator. As a result, after a period of rapid growth, uniform growth rates were observed. This is behavior expected in service whilst the tree is much shorter than the insulation length.

A strong correlation is seen between maximum partial discharge magnitude and tracking length, suggesting the largest discharges traverse the full length of the track. It is postulated that smaller discharges are responsible for infill growth within the tracking pattern, and electrical tree growth in the epoxy resin. The surface topography of the plaques, measured after testing, indicated channels that spread at the interface had widths up to $1000 \mu \mathrm{m}$. Although less evident, eroded channels were also observed on the silicone rubber interface, near to the electrode.

Once initiated by the artificial defect (the wire electrode), the track is able to propagate at a constant speed in the otherwise uniform field and geometry. In practical applications the electric field distribution along an insulator will control the track propagation. The equilibrium growth rate of the track, established once the front of the track is distant from the field-enhancing electrode, is higher under low pressure conditions. It is concluded that in a weak interface, the internal discharge activity more readily forms hollow and wide interfacial channels, which develop debonded areas and interfacial erosion. In addition, the growth of electrical trees and the formation of carbon deposits in and on the epoxy resin will further enhance the local field sufficiently to further stimulate tracking paths along the interface.

In service insulators the epoxy resin is highly filled with pultruded glass fibre, and the impact of that on treeing and tracking behavior requires further study.

\section{ACKNOWLEDGMENT}

The authors are grateful to EPSRC and The University of Manchester for a DTA grant in support of this project.

\section{REFERENCES}

[1] V. K. Agarwal, "Aging of Multistressed Polymeric Insulators," IEEE Trans. Electr. Insul., vol. 24, no. 5, pp. 741 - 763, 1989.

[2] H. Kamer and M. Ieda, "Technical aspects of interfacial phenomena in solid insulating systems," 3rd Int. Conf. Prop. Appl. Dielectr. Mater., pp. 592-597, 1991.

[3] C. H. de Tourreil, "Response of composite insulators to dynamic mechanical loads," IEEE Trans. Power Deliv., vol. 5, no. 1, pp. 379 383, 1990.

[4] T. Tanaka, "Aging of Polymeric and Composite Insulating Materials Aspects of Interfacial Performance in Aging," IEEE Trans. Dielectr. Electr. Insul., vol. 9, no. 5, pp. $704-717,2002$.

[5] H. Geene, R. Ross, D. Kunze, M. Nagao, F. Ombello, W. Strassberger, J. Cardinaels, J. Gahungu, J. Kim, J. Densley, and T. Blackburn, "Interfaces in accessories for extruded HV and EHV cables," CIGRE Joint Task Force 21/15, pp. 52-59, 2002.

[6] E. A. Cherney, "Non-ceramic insulators - A simple design that requires careful analysis," IEEE Electr. Insul. Mag., vol. 12, pp. $7-$ $15,1996$.

[7] G. H. Vaillancourt, S. Carignan, and C. Jean, "Experience with the detection of faulty composite insulators on high-voltage power lines by the electric field measurement method," IEEE Trans. Power Deliv., vol. 13, pp. 661-666, 1998.

[8] A. C. Gjærde, "Multifactor ageing models - Origin and similarities," IEEE Electr. Insul. Mag., vol. 13, pp. 6-13, 1997.

[9] J. Andersson, S. M. Gubanski, and H. Hillborg, "Properties of interfaces between silicone rubber and epoxy," IEEE Trans. Dielectr. Electr. Insul., vol. 15, no. 5, pp. 1360-1367, Oct. 2008.

[10] C. Dang and D. Fournier, "Dielectric performance of interfaces in premolded cable joints," IEEE Trans. Power Deliv., vol. 12, no. 1, pp. 29-32, 1997.

[11] B. X. Du and L. Gu, "Effects of interfacial pressure on tracking failure between XLPE and silicon rubber," IEEE Trans. Dielectr. Electr. Insul., vol. 17, no. 6, pp. 1922-1930, Dec. 2010.

[12] M. Hasheminezhad and E. Ildstad, "Application of contact analysis on evaluation of breakdown strength and PD inception field strength of solid-solid interfaces," IEEE Trans. Dielectr. Electr. Insul., vol. 19, no. 1 , pp. 1-7, 2012.

[13] L. Gu and X. R. He, "Microcavity on tracking failure of XLPE-SiR interface," Power and Energy Engineering Conference (APPEEC), pp. 1-4, 2012.

[14] J. Andersson, S. M. Gubanski, and H. Hillborg, "Properties of interfaces between silicone rubber and epoxy," IEEE Trans. Dielectr. Electr. Insul., vol. 15, no. 5, pp. 1360-1367, 2008.

[15] E. Kobayashi, F. Komori, and Y. Suzuoki, "Partial discharge degradation at insulating polymer-polymer interface," Proceedings of the International Symposium on Electrical Insulating Materials, pp. 569-572, 1998.

[16] P. D. Bastidas and S. M. Rowland, "Developing test methods for interfacial ageing in composite insulators," IEEE Conference on Electrical Insulation and Dielectric Phenomena (CEIDP), pp. 594 597, 2015. 